\title{
Pulmonary rehabilitation during induction chemoradiotherapy for lung cancer improves pulmonary function
}

\author{
Shintaro Tarumi, MD, PhD, Hiroyasu Yokomise, MD, PhD, Masashi Gotoh, MD, $\mathrm{PhD}$, \\ Yoshitaka Kasai, MD, PhD, Natsumi Matsuura, MD, PhD, Sung Soo Chang, MD, PhD, and \\ Tetsuhiko Go, MD, PhD
}

\begin{abstract}
Objective: Chemoradiotherapy for non-small cell lung cancer can impair pulmonary function, particularly when it is followed by surgery. This study aimed to document the changes in respiratory function as a result of a perioperative intensive pulmonary rehabilitation program in patients with non-small cell lung cancer who underwent induction chemoradiotherapy.
\end{abstract}

\begin{abstract}
Methods: A total of 82 consecutive patients underwent pulmonary resection after undergoing induction chemoradiotherapy. A pulmonary rehabilitation program was started at the same time as the induction chemoradiotherapy. Standard respiratory function tests were performed before and after induction chemoradiotherapy. Treatment-related mortality and the incidence of postoperative respiratory complications were investigated. The Wilcoxon signed-rank test was used to analyze the differences in spirometric changes.
\end{abstract}

Results: All patients underwent a pulmonary rehabilitation program for an average of 10 weeks. Significant increases were observed in forced vital capacity $(+6.4 \%, P=.0096)$ and forced expiratory volume in 1 second $(+10.4 \%, P<.0001)$. Diffusing capacity of the lung for carbon monoxide decreased $(-14.0 \%, P<.0001)$. Patients with respiratory impairment (forced vital capacity $<80 \%$ predicted or forced expiratory volume in 1 second/forced vital capacity $<70 \%)$ showed significant improvements in forced vital capacity $(+13.9 \%$, $P=.0025)$ and forced expiratory volume in 1 second $(+22.5 \%, P<.0001)$. Significant increases were observed in forced vital capacity $(+7.0 \%, P=.0042)$ and forced expiratory volume in 1 second $(+10.8 \%, P=.0001)$ in patients with a smoking history. There was no mortality, and postoperative respiratory morbidity was $6.1 \%$.

Conclusions: A pulmonary rehabilitation program for patients with non-small cell lung cancer undergoing induction chemoradiotherapy seems to improve respiratory function. It is particularly recommended for smokers and patients with respiratory impairment. (J Thorac Cardiovasc Surg 2015;149:569-73)

See related commentary on pages 574-5.

Chemotherapy and radiation therapy are known to affect pulmonary function, particularly when followed by surgery. ${ }^{1,2}$ The efficacy of postoperative pulmonary rehabilitation is already known, ${ }^{3,4}$ and it is recommended as Grade $1 \mathrm{C}$ by guidelines. ${ }^{5}$ However, to the best of our knowledge, the efficacy of perioperative pulmonary rehabilitation specifically in patients undergoing induction chemoradiotherapy (IT) has not been reported to date. We hypothesized that a perioperative intensive pulmonary rehabilitation program (PPRP) would improve forced expiratory volume in 1 second (FEV1). Thus, the purpose of this study was to evaluate the improvements in FEV1 and forced vital capacity (FVC)

\footnotetext{
From the Faculty of Medicine, Department of General Thoracic Surgery, Breast and Endocrinological Surgery, Kagawa University, Kagawa, Japan.

Disclosures: Authors have nothing to disclose with regard to commercial support.

Received for publication Oct 18, 2013; revisions received Sept 4, 2014; accepted for publication Sept 27, 2014; available ahead of print Nov 25, 2014.

Address for reprints: Shintaro Tarumi, MD, PhD, 1750-1 Ikenobe, Miki-cho, Kitagun, Kagawa 761-0793, Japan (E-mail: starumi@med.kagawa-u.ac.jp). $0022-5223 / \$ 36.00$

Copyright (c) 2015 by The American Association for Thoracic Surgery http://dx.doi.org/10.1016/j.jtcvs.2014.09.123
}

due to a PPRP in patients with non-small cell lung cancer (NSCLC) who underwent IT followed by surgery. Diffusing capacity of the lung for carbon monoxide (DLCO), postoperative mortality, and morbidity also were investigated in these patients who underwent IT and the PPRP.

\section{MATERIALS AND METHODS \\ Patients}

A total of 82 patients underwent pulmonary resection after IT in Kagawa University Hospital between March 2000 and November 2011. All of these patients' data were retrospectively analyzed. No other patients had undergone IT during that period. The patients' characteristics are summarized in Tables 1 and 2. All 82 patients underwent scheduled concurrent chemoradiotherapy as IT. Respiratory impairment (RI), defined as a "restrictive ventilatory defect (FVC $<80 \%$ predicted)," "obstructive respiratory event (FEV1/FVC $<70 \%$ )," or both, 6,7 were noted in 33 patients $(40.2 \%)$. All patients participated in a PPRP for 8 weeks or more (average, 10 weeks). The institutional review board of Kagawa University approved the study protocol, and all eligible patients provided their written, informed consent.

\section{Induction Chemoradiotherapy Protocol and Surgery}

The details of IT have been described. ${ }^{8}$ In brief, chemotherapy was performed on weeks 1 and 5, and concurrent radiation therapy with 50 Gy $(2 \mathrm{~Gy} / \mathrm{d}, 5 \mathrm{~d} / \mathrm{wk})$ was conducted from weeks 1 to 5 . The patients received carboplatin (area under the curve $6 \mathrm{mg} /\left[\mathrm{mL}^{*} \mathrm{~min}\right]$, 2-hour 


\section{Abbreviations and Acronyms \\ DLCO = diffusing capacity of the lung for carbon monoxide \\ FEV1 = forced expiratory volume in 1 second \\ FVC = forced vital capacity \\ IT = induction chemoradiotherapy \\ NSCLC $=$ non-small cell lung cancer \\ PPRP $=$ perioperative intensive pulmonary rehabilitation program \\ RI

$$
=\text { respiratory impairment }
$$

intravenous infusion) and docetaxel $\left(60 \mathrm{mg} / \mathrm{m}^{2}, 2\right.$-hour intravenous infusion) on day 1 . The criteria for surgery after IT followed in our department have been reported. ${ }^{8}$ Surgery consisted of anatomic resection (lobectomy, bilobectomy, and pneumonectomy), along with hilar and mediastinal systemic lymph node dissection. Adjacent organs (eg, chest wall and vertebral body) were also resected in patients in whom complete resection was required. Surgery was performed through a thoracotomy 4 to 6 weeks after the end of IT.

\section{Perioperative Intensive Pulmonary Rehabilitation Program}

Our program was assembled on the basis of various studies and, as a result, was approximately the same as the established guidelines. ${ }^{9,10}$ The details of the program are as follows. After the beginning of IT, patients received a PPRP that was continued until the surgical procedure was completed and the patients were discharged from hospital. The patients were managed daily by the thoracic team, which consisted of thoracic surgeons, physicians, physiotherapists, and nurses. All patients were in the hospital for the entire duration of IT; therefore, the PPRP was mainly performed in the physiotherapy room except for the day of surgery. The PPRP essentially consisted of education, relaxation, respiratory and cough training, and lower-extremity exercise as detailed next.

1. Relaxation: Relaxation was performed 1 or more times per day during the PPRP, so that the patients learned the technique of breathing with muscular relaxation to control the activity of auxiliary breathing muscles and decrease basal metabolism.

2. Respiratory training: Respiratory training consisted of diaphragmatic breathing, expiratory muscle training with incentive spirometry (Voldyne 5000, Sherwood Medical, St Louis, Mo; Souffle, Kayaku Co, Ltd, Tokyo, Japan), leg raising synchronized with diaphragmatic breathing, and training of trunk muscles focusing on abdominal muscles performed 1 or more times per day before surgery.

3. Cough training: Cough training involved the teaching of an effective cough method to maintain purging of the respiratory tract, or if coughing was difficult, huffing was taught and performed once daily before surgery.

4. Lower-extremity exercise: Stationary cycle ergometry was performed while monitoring the heart rate for 45 minutes, 5 days per week as high-intensity aerobic exercise training.

5. Training in activities of daily living: Training in activities of daily living, which included standing up and walking associated with early postoperative ambulation, was started on the day after the operation.

\section{Treatment for Chronic Obstructive Pulmonary Disease}

Patients with chronic obstructive pulmonary disease also received medication based on the global strategy of the Global Initiative for Chronic
Obstructive Lung Disease. ${ }^{7}$ The primary medical treatment was the use of a bronchodilator, and steroids were used depending on the patient's condition.

\section{Smoking Cessation}

Smoking cessation was requested of all current smokers at the time of the first medical examination. Medical intervention, for example, counseling and nicotine replacement therapy, was provided to the patients if needed. The duration of smoking cessation was at least 4 weeks when IT was started. Smoking cessation was maintained after treatment.

\section{Respiratory Function Evaluation}

Standard respiratory function tests were performed pre-IT and 2 weeks post-IT to compare FVC, FEV1, and DLCO. Post-IT DLCO was performed in 47 patients with low pre-IT DLCO or in patients for whom pneumonectomy was planned. Predicted values of FVC, FEV1, and DLCO were calculated using previously published equations and data on patient age, sex, and height. ${ }^{11,12}$

\section{Statistical Analysis}

The data are expressed as means \pm standard deviation. The differences between the spirometric values of pre-IT and post-IT measurements were analyzed by the Wilcoxon signed-rank test. Student $t$ test was used for comparison of the mean values of 2 groups. The chi-square test was used to evaluate differences in morbidity rates. Statistical analysis of the data was performed using the Statistical Package for the Social Sciences for Windows, version 20.0.0 (IBM SPSS, Chicago, Ill).

\section{RESULTS}

The pre-IT and post-IT spirometric measurements are shown in Table 3 and Figure 1. Significant increases were observed in FVC and FEV1 $(P=.0096, P<.0001$, respectively). Patients with RI showed a significantly greater increase in FVC and FEV1 than those without RI $(P=.0048, P<.0001$, respectively). Post-IT DLCO decreased significantly regardless of the presence or absence of RI. Current and former smokers showed significant improvements in FEV1 $(P=.0082, P=.0086$, respectively) (Table 4). There was no treatment-related mortality, and respiratory morbidity was $6.1 \%(5 / 82: 3$ due to pneumonia and 2 due to hypoxemia with home oxygen therapy). The incidence of postoperative respiratory morbidity was not significantly different between patients with and without RI: $6.1 \%$ (2/33) and 6.1\% (3/49), respectively $(P=.9908)$.

\section{DISCUSSION}

Some analyses of changes in respiratory function with IT for locally advanced NSCLC have been reported. Margaritora and colleagues ${ }^{1}$ reported that changes in FVC, FEV1, and DLCO were $-2.4 \%,-3.5 \%$, and $-22.8 \%$, respectively. Cerfolio and colleagues ${ }^{13}$ reported that FEV1 and DLCO changed $+1.0 \%$ and $-6.4 \%$, respectively. Takeda and colleagues ${ }^{14}$ reported that DLCO decreased $-21 \%$. The present study of patients who underwent the PPRP showed significant increases of FVC and FEV1 in patients who received IT for NSCLC. Furthermore, a marked 
TABLE 1. Patients' characteristics

\begin{tabular}{lcr}
\hline \multicolumn{1}{c}{ Characteristic } & No. & $\%$ \\
\hline Age, y, mean (range) & $64(37-78)$ & \\
Clinical stage & & \\
2B & 4 & 4.9 \\
3A & 48 & 58.5 \\
3B & 27 & 32.9 \\
4 & 3 & 3.7 \\
Smoking status & & \\
Current & 41 & 50.0 \\
Former & 33 & 40.2 \\
$\quad$ Never & 8 & 9.8 \\
RI & 33 & 40.2 \\
Obstructive respiratory event ${ }^{*}$ & 21 & 25.6 \\
Restrictive ventilatory defect $\dagger$ & 7 & 8.5 \\
Combined ventilatory impairment $\ddagger$ & 5 & 6.1 \\
\hline RI, Respiratory impairment. ${ }^{*}$ FEV1/FVC $<70 \%$. & $\dagger$ FVC $<80 \%$ predicted. $\ddagger$ Both \\
obstructive and restrictive. & &
\end{tabular}

improvement was observed in those with RI. These results imply that there was an association between the PPRP and the improvement of pulmonary function. However, the present study was a retrospective, observational study with no control group. Therefore, the results must be interpreted carefully. The decreasing DLCO with IT is considered to be caused by injury to the alveolar wall. ${ }^{2}$ Therefore, it is difficult for patients who receive IT to improve DLCO through exercise training. We consider that time is necessary for the recovery of DLCO. In other words, when post-IT DLCO decreases to lower than the value that guidelines recommend, postponement of the operation should be considered, if necessary.

Morbidity and mortality rates after pulmonary resection have decreased over time, and the 30-day mortality of patients with lung cancer undergoing lobectomy is $0.3 \%$ in Japan. ${ }^{15}$ However, postoperative mortality after surgical resection in patients with lung cancer who received IT is still high $(1.8 \%-9.8 \%) .{ }^{1,13,14,16,17}$ These studies showed that postoperative respiratory complications, such as acute respiratory distress syndrome, accounted for a high

TABLE 2. Outcome measures

\begin{tabular}{lcc}
\hline & No. & $\%$ \\
\hline Surgical procedures & & \\
$\quad$ Pneumonectomy* & 25 & 30.5 \\
$\quad$ Lobectomy $\dagger$ & 57 & 69.5 \\
Complete resection (R0) & 81 & 98.8 \\
Postoperative complications & & \\
$\quad$ Pneumonia & 3 & 3.7 \\
$\quad$ Hypoxemia requiring home oxygen therapy & 2 & 2.4 \\
Postoperative treatment-related death & 0 & 0 \\
\hline
\end{tabular}

*Including sleeve pneumonectomy and pneumonectomy with vertebral resection. $\dagger$ Including sleeve lobectomy, bilobectomy, and lobectomy with chest wall resection and lobectomy with vertebral resection. percentage of postoperative deaths (71.4\%-90.9\%) Compromised pulmonary function is known to elevate the risks of postoperative morbidity and mortality. ${ }^{18,19}$ Furthermore, chemoradiotherapy generally leads to decreasing pulmonary function. ${ }^{1,2}$ In brief, IT can increase perioperative morbidity and mortality, mainly because of respiratory events. ${ }^{20,21}$ Barnett and colleagues $^{16}$ showed that predicted postoperative FEV1 was the best predictor of postoperative complications. Predicted postoperative DLCO and baseline DLCO were also found to be the best predictors of postoperative mortality. The predicted postoperative product, which is affected by FEV1 and DLCO, is correlated with perioperative risks. ${ }^{16,22}$ These results showed that FEV1 was one of the important factors for assessment of the appropriateness of surgery. It was an important finding that improvement of FEV1 was observed during IT in the patients in the present study. The improvement in FEV1, particularly in patients with RI, due to the PPRP may have contributed to a reduction in the incidence of postoperative complications. The present study showed that there was no difference in the incidence of postoperative complications between the RI group and the normal group $(6.1 \%$ vs $6.1 \% ; P=.9908)$. Morbidity in the present study was low in comparison with past reports (6.1\% vs $13.8 \%-33.3 \%) .{ }^{13,14,23}$ Albain and colleagues ${ }^{17}$ reported high mortality (25.9\%) in patients who underwent pneumonectomy after IT. The present study included patients who underwent pneumonectomy ( 25 cases), but the mortality rate and incidence of complications were low ( $0 \%$ and $6.1 \%$, respectively).

Smoking has been found to be a risk factor for the development of postoperative complications after surgery. ${ }^{24} \mathrm{Bar}-$ rera and colleagues ${ }^{25}$ reported that smoking increased the incidence of postoperative pneumonia and the length of hospital stay. Significant improvements of respiratory function in smokers were observed in the present study, which may be related to the low postoperative complication rate.

\section{Study Limitations}

The limitations of the present study include the fact that other factors involved in surgical tolerance, including 6minute walking distance and maximal oxygen consumption peak, were not analyzed. Future studies evaluating these parameters are necessary. The relationship of the PPRP to the incidence of morbidity and mortality could not be rigorously evaluated because only patients who underwent IT and performed the PPRP at the Kagawa University were studied. Furthermore, this was a retrospective study. Therefore, these results should be interpreted judiciously. Although accurate PPRP evaluation needs a randomized, controlled trial, assigning patients to a control group is ethically difficult, because pulmonary rehabilitation is already recommended by guidelines. At the Kagawa University, 
TABLE 3. Spirometric parameters, ${ }^{*}$ pre- and post-induction chemoradiotherapy, of all patients and patients with respiratory impairment

\begin{tabular}{|c|c|c|c|c|}
\hline Parameters & Pre-IT & Post-IT & Difference $\dagger(\%)$ & $P$ value $\ddagger$ \\
\hline FVC (L) & $3.10 \pm 0.70$ & $3.23 \pm 0.66$ & $+0.14 \pm 0.44(+6.4 \% \pm 18.1 \%)$ & .0096 \\
\hline With RI & $2.74 \pm 0.77$ & $3.04 \pm 0.78$ & $+0.30 \pm 0.55(+13.9 \% \pm 24.9 \%)$ & .0025 \\
\hline Without RI & $3.34 \pm 0.54$ & $3.36 \pm 0.53$ & $+0.03 \pm 0.31(+1.3 \% \pm 8.8 \%)$ & .5116 \\
\hline$\% \mathrm{FVC}(\%)$ & $95.6 \pm 18.6$ & $101.4 \pm 13.4$ & $+4.3 \pm 13.5$ & .0066 \\
\hline With RI & $88.1 \pm 22.6$ & $97.4 \pm 20.7$ & $+9.3 \pm 17.0$ & .0022 \\
\hline Without RI & $100.6 \pm 13.3$ & $101.4 \pm 13.4$ & $+0.9 \pm 9.4$ & .4769 \\
\hline FEV1 (L) & $2.26 \pm 0.65$ & $2.42 \pm 0.58$ & $+0.16 \pm 0.35(+10.4 \% \pm 21.2 \%)$ & $<.0001$ \\
\hline With RI & $1.70 \pm 0.47$ & $2.04 \pm 0.55$ & $+0.34 \pm 0.41(+22.5 \% \pm 27.4 \%)$ & $<.0001$ \\
\hline Without RI & $2.64 \pm 0.45$ & $2.68 \pm 0.44$ & $+0.05 \pm 0.25(+2.3 \% \pm 9.4 \%)$ & .1370 \\
\hline$\%$ FEV1 $(\%)$ & $88.5 \pm 21.1$ & $96.1 \pm 18.3$ & $+7.5 \pm 16.5$ & .0002 \\
\hline With RI & $73.0 \pm 20.2$ & $89.1 \pm 21.5$ & $+16.0 \pm 20.4$ & .0002 \\
\hline Without RI & $99.0 \pm 14.3$ & $100.8 \pm 14.2$ & $+1.8 \pm 9.8$ & .1945 \\
\hline $\mathrm{DLCO}(\mathrm{mL} / \mathrm{min} / \mathrm{mm} \mathrm{Hg})$ & $15.14 \pm 5.81$ & $13.05 \pm 5.52$ & $-2.09 \pm 2.33(-14.0 \% \pm 16.0 \%)$ & $<.0001$ \\
\hline With RI & $13.05 \pm 5.19$ & $11.33 \pm 5.17$ & $-1.72 \pm 2.48(-13.8 \% \pm 20.9 \%)$ & .0126 \\
\hline Without RI & $16.56 \pm 5.86$ & $14.21 \pm 5.53$ & $-2.34 \pm 2.23(-14.0 \% \pm 12.0 \%)$ & $<.0001$ \\
\hline$\%$ DLCO $(\%)$ & $86.9 \pm 23.4$ & $75.6 \pm 22.5$ & $-11.4 \pm 14.2$ & $<.0001$ \\
\hline With RI & $77.4 \pm 23.0$ & $68.1 \pm 24.3$ & $-9.3 \pm 16.6$ & .0242 \\
\hline Without RI & $93.4 \pm 21.8$ & $80.6 \pm 20.2$ & $-12.8 \pm 12.4$ & $<.0001$ \\
\hline
\end{tabular}

$\overline{D L C O}$, Diffusing capacity of the lung for carbon monoxide; \%DLCO, percentage of predicted DLCO; $F E V 1$, forced expiratory volume in 1 second; \% $F E V I$, percentage of predicted FEV1; FVC, forced vital capacity; \%FVC, percentage of predicted FVC; $I T$, induction chemoradiotherapy; RI, respiratory impairment (FEV1/FVC $<70 \%$ or FVC $<80 \%$ predicted). *Data are expressed as means with standard deviations. †Difference between post-IT and pre-IT values. †Wilcoxon signed-rank test.

all patients undergoing lung surgery have been undergoing the PPRP. This study was performed over a long time period, which raised some concerns about the consistency of PPRP methods. However, our methods used in the
PPRP have not changed throughout the whole period, as seen in the American College of Chest Physicians Evidence-Based Clinical Practice guidelines from the first and third editions. ${ }^{5}$

TABLE 4. Spirometric parameters, ${ }^{*}$ pre- and post-induction chemoradiotherapy, of patients classified by smoking status

\begin{tabular}{|c|c|c|c|c|}
\hline Parameters & Pre-IT & Post-IT & Difference $\dagger(\%)$ & $P$ value \\
\hline \multicolumn{5}{|l|}{$\mathrm{FVC}(\mathrm{L})$} \\
\hline Current & $3.12 \pm 0.70$ & $3.25 \pm 0.71$ & $+0.13 \pm 0.44(+5.5 \% \pm 16.9 \%)$ & .1328 \\
\hline Former & $3.03 \pm 0.68$ & $3.22 \pm 0.60$ & $+0.19 \pm 0.47(+8.9 \% \pm 21.1 \%)$ & .0212 \\
\hline Never & $3.26 \pm 0.86$ & $3.23 \pm 0.71$ & $-0.02 \pm 0.28(-0.6 \% \pm 7.7 \%)$ & .7353 \\
\hline \multicolumn{5}{|l|}{$\% \mathrm{FVC}(\%)$} \\
\hline Current & $94.4 \pm 17.5$ & $98.4 \pm 18.7$ & $+4.0 \pm 13.3$ & .1124 \\
\hline Former & $93.7 \pm 18.3$ & $99.5 \pm 14.0$ & $+5.8 \pm 14.6$ & .0197 \\
\hline Never & $109.0 \pm 21.6$ & $108.4 \pm 15.4$ & $-0.6 \pm 9.5$ & .7794 \\
\hline \multicolumn{5}{|l|}{ FEV1 (L) } \\
\hline Current & $2.21 \pm 0.70$ & $2.38 \pm 0.65$ & $+0.17 \pm 0.36(+10.8 \% \pm 21.9 \%)$ & .0082 \\
\hline Former & $2.29 \pm 0.59$ & $2.46 \pm 0.52$ & $+0.17 \pm 0.37(+10.8 \% \pm 21.6 \%)$ & .0086 \\
\hline Never & $2.41 \pm 0.69$ & $2.50 \pm 0.60$ & $+0.08 \pm 0.27(+6.4 \% \pm 16.4 \%)$ & .2076 \\
\hline \multicolumn{5}{|l|}{$\%$ FEV1 $(\%)$} \\
\hline Current & $84.1 \pm 20.5$ & $93.2 \pm 20.4$ & $+9.1 \pm 17.4$ & .0032 \\
\hline Former & $91.5 \pm 20.8$ & $98.3 \pm 16.7$ & $+6.8 \pm 15.6$ & .0273 \\
\hline Never & $99.3 \pm 22.1$ & $101.4 \pm 11.8$ & $+2.1 \pm 15.4$ & .4990 \\
\hline \multicolumn{5}{|c|}{$\operatorname{DLCO}(\mathrm{mL} / \mathrm{min} / \mathrm{mm} \mathrm{Hg})$} \\
\hline Current & $15.09 \pm 6.35$ & $13.33 \pm 5.78$ & $-1.76 \pm 2.50(-11.5 \% \pm 18.2 \%)$ & .0026 \\
\hline Former & $14.92 \pm 4.30$ & $12.31 \pm 4.26$ & $-2.61 \pm 2.23(-17.7 \% \pm 13.4 \%)$ & .0002 \\
\hline Never & $16.95 \pm 10.98$ & $15.39 \pm 11.08$ & $-1.56 \pm 1.09(-11.0 \% \pm 8.2 \%)$ & .1088 \\
\hline \multicolumn{5}{|l|}{$\%$ DLCO $(\%)$} \\
\hline Current & $83.7 \pm 27.1$ & $74.9 \pm 25.7$ & $-8.8 \pm 15.2$ & .0068 \\
\hline Former & $90.3 \pm 16.8$ & $75.5 \pm 18.2$ & $-14.8 \pm 12.8$ & .0003 \\
\hline Never & $92.7 \pm 30.9$ & $81.9 \pm 26.7$ & $-10.8 \pm 13.3$ & .1088 \\
\hline
\end{tabular}

$D L C O$, Diffusing capacity of the lung for carbon monoxide; $\% D L C O$, percentage of predicted DLCO; $F E V I$, forced expiratory volume in 1 second; $\% F E V I$, percentage of predicted FEV1; FVC, forced vital capacity; $\% F V C$, percentage of predicted FVC; $I T$, induction chemoradiotherapy. *Data are expressed as means with standard deviations. $\dagger$ Difference between post-IT and pre-IT values. ‡Wilcoxon signed-rank test. 


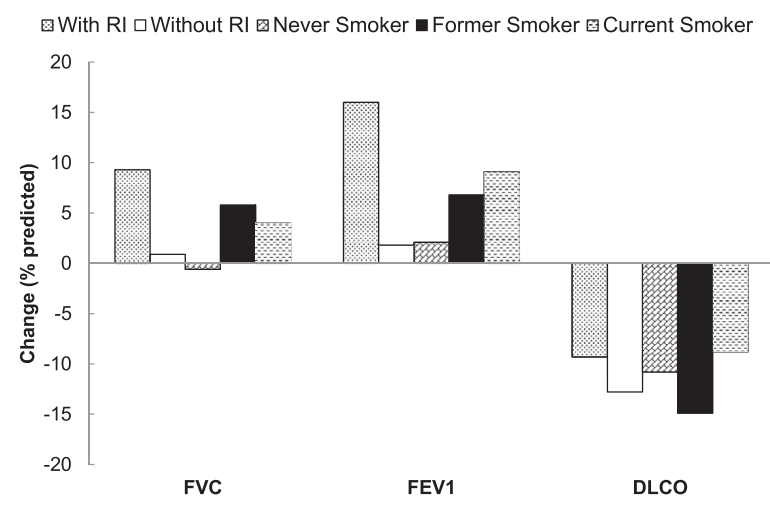

FIGURE 1. Changes* of spirometric parameters. DLCO, Diffusing capacity of the lung for carbon monoxide; $F E V I$, forced expiratory volume in 1 second; $F V C$, forced vital capacity; $R I$, respiratory impairment (FEV1/FVC $<70 \%$ or FVC $<80 \%$ predicted). *Changes between postIT and pre-IT values are expressed as $\%$ of predicted normal.

\section{CONCLUSIONS}

The present study showed that patients who underwent the PPRP during IT had improved respiratory function. All smokers and patients with RI who underwent the PPRP during IT showed improvements in FVC and FEV1. Because there was no control group (with no PPRP) in the present study, these results should be interpreted judiciously. However, these findings suggest that the PPRP has efficacy for smokers and patients with RI. Further investigations of the role of the PPRP are needed.

\section{References}

1. Margaritora S, Cesario A, Cusumano G, Cafarotti S, Corbo GM, Ferri L, et al. Is pulmonary function damaged by neoadjuvant lung cancer therapy? A comprehensive serial time-trend analysis of pulmonary function after induction radiochemotherapy plus surgery. J Thorac Cardiovasc Surg. 2010; 139:1457-63.

2. McDonald S, Rubin P, Phillips TL, Marks LB. Injury to the lung from cancer therapy: clinical syndromes, measurable endpoints, and potential scoring systems. Int J Radiat Oncol Biol Phys. 1995;31:1187-203.

3. Cesario A, Ferri L, Galetta D, Pasqua F, Bonassi S, Clini E, et al. Post-operative respiratory rehabilitation after lung resection for non-small cell lung cancer. Lung Cancer. 2007;57:175-80.

4. Glattki GP, Manika K, Sichletidis L, Alexe G, Brenke R, Spyratos D. Pulmonary rehabilitation in non-small cell lung cancer patients after completion of treatment. Am J Clin Oncol. 2012;35:120-5.

5. Brunelli A, Kim AW, Berger KI, Addrizzo-Harris DJ. Physiologic evaluation of the patient with lung cancer being considered for resectional surgery: diagnosis and management of lung cancer, 3rd ed: American College of Chest Physicians evidence-based clinical practice guidelines. Chest. 2013;143: e166S-90S.

6. Wheaton AG, Ford ES, Thompson WW, Greenlund KJ, Presley-Cantrell LR, Croft JB. Pulmonary function, chronic respiratory symptoms, and health-related quality of life among adults in the United States-National Health and Nutrition Examination Survey 2007-2010. BMC Public Health. 2013;13:854.

7. Global Initiative for Chronic Obstructive Lung Disease. The Global Strategy for the Diagnosis, Management and Prevention of Chronic Obstructive Lung Disease, Revised 2011. February 2011. Available at: http://www.goldcopd. org/uploads/users/files/GOLD_Report_2011_Feb21.pdf. Accessed Sept 27, 2012.

8. Yokomise H, Gotoh M, Okamoto T, Yamamoto Y, Ishikawa S, Nakashima T, et al. Induction chemoradiotherapy (carboplatin-taxane and concurrent 50-Gy radiation) for bulky cN2, N3 non-small cell lung cancer. J Thorac Cardiovasc Surg. 2007; 133:1179-85.

9. Nici L, Donner C, Wouters E, Zuwallack R, Ambrosino N, Bourbeau J, et al. American Thoracic Society/European Respiratory Society statement on pulmonary rehabilitation. Am J Respir Crit Care Med. 2006;173:1390-413.

10. Ries AL, Bauldoff GS, Carlin BW, Casaburi R, Emery CF, Mahler DA, et al Pulmonary rehabilitation: joint ACCP/AACVPR Evidence-Based Clinical Practice Guidelines. Chest. 2007;131:4S-42S.

11. Baldwin ED, Cournand A, Richards DW Jr. Pulmonary insufficiency; physiological classification, clinical methods of analysis, standard values in normal subjects. Medicine (Baltimore). 1948;27:243-78.

12. Macintyre N, Crapo RO, Viegi G, Johnson DC, van der Grinten CP, Brusasco V, et al. Standardisation of the single-breath determination of carbon monoxide uptake in the lung. Eur Respir J. 2005;26:720-35.

13. Cerfolio RJ, Talati A, Bryant AS. Changes in pulmonary function tests after neoadjuvant therapy predict postoperative complications. Ann Thorac Surg. 2009; 88:930-5.

14. Takeda S, Funakoshi Y, Kadota Y, Koma M, Maeda H, Kawamura S, et al. Fall in diffusing capacity associated with induction therapy for lung cancer: a predictor of postoperative complication? Ann Thorac Surg. 2006;82:232-6.

15. Amano J, Kuwano H, Yokomise H. Thoracic and cardiovascular surgery in Japan during 2011: annual report by The Japanese Association for Thoracic Surgery. Gen Thorac Cardiovasc Surg. 2013;61:578-607.

16. Barnett SA, Rusch VW, Zheng J, Park BJ, Rizk NP, Plourde G, et al. Contemporary results of surgical resection of non-small cell lung cancer after induction therapy: a review of 549 consecutive cases. J Thorac Oncol. 2011;6: 1530-6.

17. Albain KS, Swann RS, Rusch VW, Turrisi AT III, Shepherd FA, Smith C, et al Radiotherapy plus chemotherapy with or without surgical resection for stage III non-small-cell lung cancer: a phase III randomised controlled trial. Lancet. 2009; 374:379-86.

18. Berry MF, Villamizar-Ortiz NR, Tong BC, Burfeind WR Jr, Harpole DH, D'Amico TA, et al. Pulmonary function tests do not predict pulmonary complications after thoracoscopic lobectomy. Ann Thorac Surg. 2010;89: 1044-51.

19. Ferguson MK, Siddique J, Karrison T. Modeling major lung resection outcomes using classification trees and multiple imputation techniques. Eur J Cardiothorac Surg. 2008;34:1085-9.

20. Doddoli C, Thomas P, Thirion X, Seree Y, Giudicelli R, Fuentes P. Postoperative complications in relation with induction therapy for lung cancer. Eur J Cardiothorac Surg. 2001;20:385-90.

21. Matsubara Y, Takeda S, Mashimo T. Risk stratification for lung cancer surgery: impact of induction therapy and extended resection. Chest. 2005;128:3519-25.

22. Pierce RJ, Copland JM, Sharpe K, Barter CE. Preoperative risk evaluation for lung cancer resection: predicted postoperative product as a predictor of surgical mortality. Am J Respir Crit Care Med. 1994;150:947-55.

23. Evans NR 3rd, Li S, Wright CD, Allen MS, Gaissert HA. The impact of induction therapy on morbidity and operative mortality after resection of primary lung cancer. J Thorac Cardiovasc Surg. 2010;139:991-6.

24. Kearney DJ, Lee TH, Reilly JJ, DeCamp MM, Sugarbaker DJ. Assessment of operative risk in patients undergoing lung resection. Importance of predicted pulmonary function. Chest. 1994;105:753-9.

25. Barrera R, Shi W, Amar D, Thaler HT, Gabovich N, Bains MS, et al. Smoking and timing of cessation: impact on pulmonary complications after thoracotomy. Chest. 2005; 127:1977-83. 